\title{
Magnetic resonance and near infrared spectroscopy for investigation of perinatal hypoxic-ischaemic brain injury
}

\author{
J S WYATT, A D EDWARDS, D AZZOPARDI, AND E O R REYNOLDS \\ Department of Paediatrics, University College and Middlesex School of Medicine, London
}

The introduction of non-invasive methods for the assessment of cerebral structure and function has been one of the most exciting recent developments in neonatal paediatrics. The availability of these methods permits the incidence and mechanisms of potentially brain damaging influences to be explored, preventive measures and treatments to be tested, and the prognosis of small sick infants to be determined with reasonable confidence. The ability to study these problems has important implications for the conduct of neonatal intensive care.

Ultrasound imaging has proved to be a particularly useful method that has provided much information about cerebral (periventricular) haemorrhage in preterm infants. It has also confirmed the serious prognostic significance of the most florid lesions of periventricular leucomalacia, which results from hypoxic-ischaemic brain injury. Follow up studies of cohorts of preterm infants prospectively studied with ultrasound imaging leave us in little doubt that hypoxic-ischaemic injury is a more important cause of permanent neurodevelopmental disability in surviving very preterm infants than periventricular haemorrhage. Birth asphyxia in infants born at full term also causes hypoxic-ischaemic injury to the brain and accounts for more disabled survivors in the community than result from very preterm birth. ${ }^{1}$ It seems clear that hypoxic-ischaemic injury is the commonest cause of perinatally acquired damage to the brain.

The purpose of this review is to describe two relatively new methods for the non-invasive investigation of this type of brain injury: magnetic resonance spectroscopy and near infrared spectroscopy. They provide complementary information about cerebral oxygenation and haemodynamics and are likely to become widely used for clinical as well as research purposes.

\section{Magnetic resonance spectroscopy}

The first observations of the human brain by magnetic resonance spectroscopy were made in the early 1980s from newborn infants. ${ }^{23}$ For observations to be made, the baby has to be transported to the spectrometer and inserted within the bore of a superconducting magnet. The studies are conducted well within National Radiological Protection Board guidelines and the technique seems completely safe, provided that care is taken to exclude ferromagnetic metal from the vicinity of the magnet. The infants can be monitored and if necessary mechanically ventilated during the studies, but ethical constraints preclude the transport of unstable babies to the magnet for research purposes.

Magnetic resonance spectroscopy can be used to measure the concentrations in brain tissue of phos-

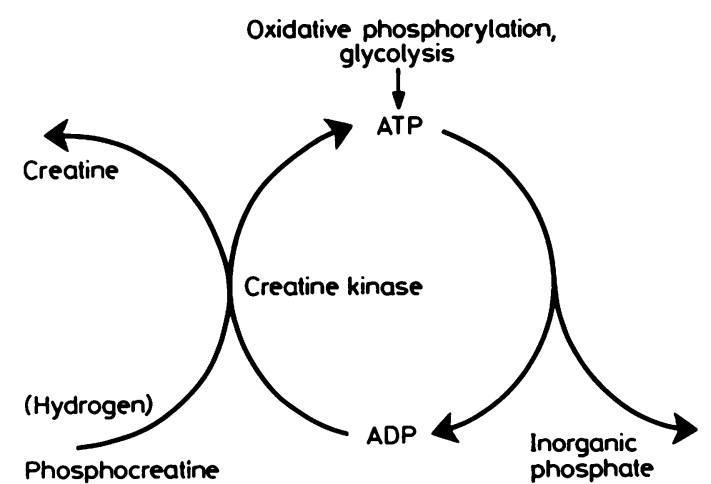

Fig 1 'High energy' phosphorus energetics. ATP, phosphocreatine (PCr) and inorganic phosphate (Pi) can be measured by magnetic resonance spectroscopy. 
phorus metabolites that are important in energy metabolism, notably adenosine triphosphate [ATP], phosphocreatine [PCr] and inorganic orthophosphate $[\mathrm{Pi}] .{ }^{4}$ Intracellular $\mathrm{pH}$ can also be measured. In situations where oxidative phosphorylation is impaired, either because the oxygen supply to the brain is reduced, or the mechanisms for consuming oxygen are damaged, [ATP] will fall (fig 1); the fall is initially extremely small, however, because of the buffering effect of the creatine kinase reaction. This reaction maintains [ATP] close to normal, but $[\mathrm{PCr}]$ falls and $[\mathrm{Pi}]$ increases-in other words the $[\mathrm{PCr}] /[\mathrm{Pi}]$ ratio decreases. This ratio is proportional to the phosphorylation potential ([ATP]/[ADP][Pi]) of the tissue and is commonly used as a measure of its energy reserve: [ATP] becomes appreciably depleted only when the [PCr] has fallen to a very low level.

The principle of the technique depends on the fact that the nuclei of phosphorus and certain other atoms, for example hydrogen, ${ }^{13}$ carbon, sodium, and fluorine have a magnetic moment. They tend to align themselves along the strong magnetic field. If a radio frequency pulse at the appropriate wavelength is applied at right angles to the field by a coil on the surface of the baby's head, this alignment is disturbed. When the pulse ceases, the nuclei return to their previous alignment and generate a magnetic resonance signal, which can be detected. The frequency or frequencies of the signal defines the compounds present, and the signal intensity is proportional to concentration.

THE NORMAL BRAIN

Fig 2 shows phosphorus spectra from the temporoparietal cortex of two infants with normal brains, one (a) born three months preterm, and the other (b) born at full term. The seven numbered spectral peaks are attributable, from left to right, to (1) phosphomonoesters, (2) Pi, (3) phosphodiesters, (4) $\mathrm{PCr}$, and (5), (6), and (7), the $\gamma, \alpha$, and $\beta$ phosphorus nuclei of nucleotide triphosphates, mainly ATP. The $x$ axis is a frequency axis and the $y$ axis is signal intensity: the areas under the peaks are proportional to concentration. The $\mathrm{PCr}$ peak is proportionately larger and the $\mathrm{Pi}$ peak smaller in the full term than in the preterm infant. Studies of a group of 30 infants with normal brains have shown that $[\mathrm{PCr}] /[\mathrm{Pi}]$ increased significantly with maturation of the brain from 27 to 42 weeks' gestational plus postnatal age, implying an increase in phosphorylation potential. ${ }^{5}$ At the same time the relative concentration of phosphomonoesters (mainly phosphoethanolamine) fell and that of phosphodiesters (including phosphatidylcholine and phosphatidylethanolamine) rose. These changes are related to the increasing complexity of membranes and to the
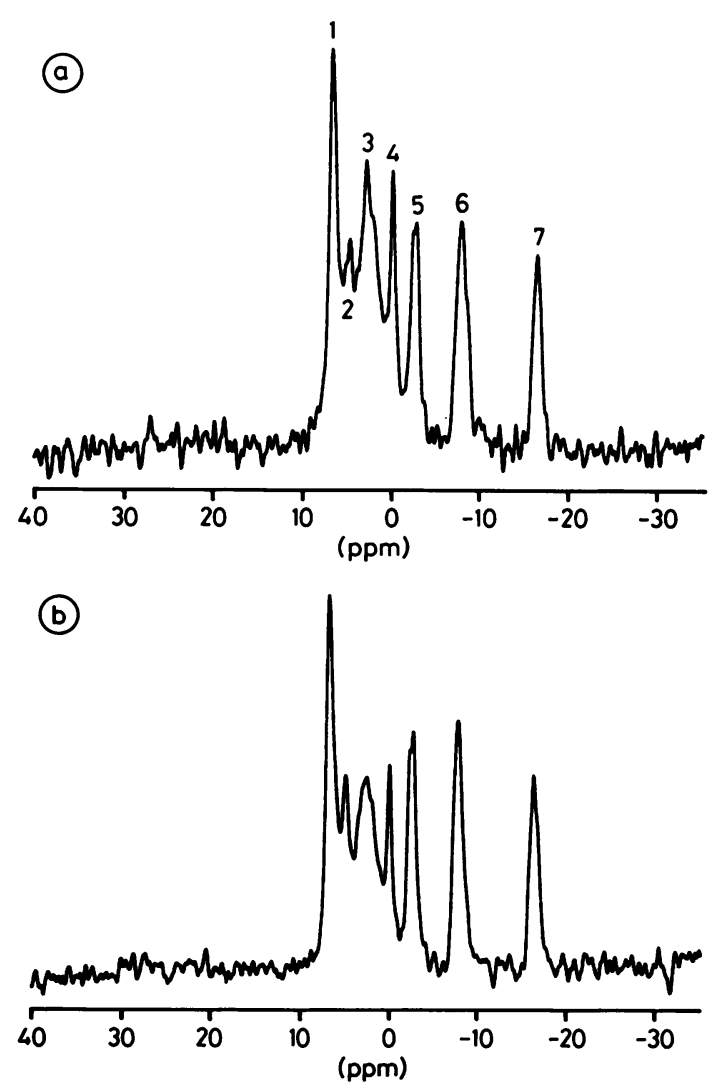

Fig 2 Phosphorus spectra from two infants with normal brains: (a) born at term and (b) born at 28 weeks' gestation; both were studied during the first week of life. The $x$ axis is chemical shift (ppm) relative to the resonance frequency of $P C r$, and the $y$ axis is signal intensity. The peaks (1-7) are attributable to phosphomonoesters, Pi, phosphodiesters, $P C r$, and the $\gamma, \alpha$, and $\beta$ phosphorus nuclei of $A T P$, respectively. (Data of Azzopardi et al. ${ }^{5}$ )

formation of myelin. Data from infants who were small for gestational age but otherwise healthy seemed no different from those from appropriately grown infants. Cerebral intracellular pH (measured by a version of the Henderson-Hasselbach equation from the difference in resonance frequency between $\mathrm{PCr}$ and $\mathrm{Pi}^{6}$ ) appeared not to change with gestation and was about $7 \cdot 10$ to $7 \cdot 15$.

Phosphorus spectra from the brains of newborn animals show changes similar to those found in the human infant. By comparison, the infant seems to 
be at about the same stage of maturation, in terms of phosphorus metabolites, as other altricious animals such as the rat, but less mature than the lamb or guinea pig, which are precocious. ${ }^{78}$

\section{HYPOXIC-ISCHAEMIC BRAIN INJURY}

\section{Birth asphyxia}

Birth asphyxia is the form of injury most thoroughly studied by magnetic resonance spectroscopy so far. $^{29-13}$ The acute effects of severe interruption of oxygen supply to the brain of the human infant during labour have not been investigated for practical reasons, but some inferences about the likely changes may be drawn from the results of studies of laboratory animals. ${ }^{14-17}$

Fig 3 shows spectra from a newborn lamb whose cerebral oxygen supply was acutely curtailed by clamping the carotid arteries and reducing the arterial oxygen tension $\left(\mathrm{PaO}_{2}\right) \cdot{ }^{14}$ During the hypoxicischaemic episode $[\mathrm{PCr}]$ fell sharply, $[\mathrm{Pi}]$ rose greatly, and [ATP] became depleted. At the same time the intracellular $\mathrm{pH}$ fell to 6.38 as a result of the production of lactic acid, with the intracerebral lactate concentration, measured by ${ }^{1} \mathrm{H}$ (proton) magnetic resonance spectroscopy, increasing to $11 \mathrm{mmol} \cdot \mathrm{kg}^{-1}$. When brain oxygenation was restored, considerable recovery had occurred by two hours. Similar results have been found in various animal species and confirm that recovery of the phosphorus metabolites and intracellular $\mathrm{pH}$ after a severe hypoxic-ischaemic episode can be rapid-and often complete within an hour or so ${ }^{14} 15$-though lactate may sometimes persist in brain tissue after the intracellular $\mathrm{pH}$ has returned to normal. ${ }^{14}$

The effects of intravenous infusion of glucose solution during, and sodium bicarbonate after, a severe ischaemic episode have been tested in lambs. ${ }^{15}$ In newborn rabbits the results of bicarbonate infusion after moderate hypoxaemia have also been observed. ${ }^{16}$ The main finding was that in none of the studies were important adverse effects in reducing intracellular $\mathrm{pH}$ detected-a conclusion that seems at variance with previous investigations using other methods in adult animals. ${ }^{18}$ In another study the effects of alterations in arterial carbon dioxide tension $\left(\mathrm{PaCO}_{2}\right)$ on intracellular $\mathrm{pH}$ were observed in lambs: homoeostasis seemed rather greater than expected. ${ }^{8}$

Studies of newborn infants who have sustained severe birth asphyxia show, perhaps surprisingly, that the phosphorus spectra and intracellular $\mathrm{pH}$ were often normal on the first day of life, but abnormalities developed during the next few days in spite of satisfactory values for $\mathrm{PaO}_{2}, \mathrm{PaCO}_{2}, \mathrm{pH}$, and blood glucose concentrations. ${ }^{9-13}$ The abnor-
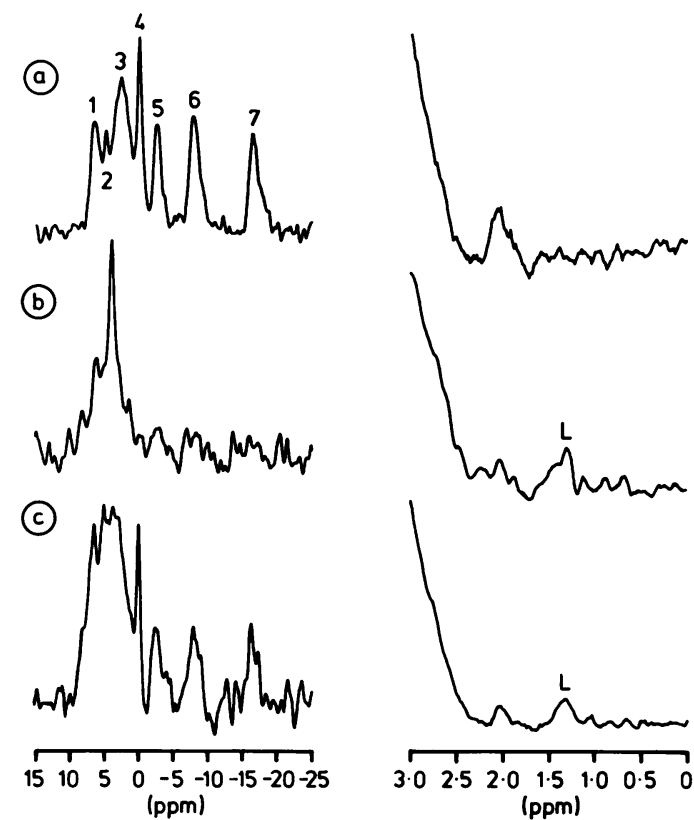

Fig 3 Phosphorus (left) and proton $\left({ }^{l} \mathrm{H}\right)$ (right) spectra from the brain of a newborn lamb. The peak assignments (1-7) are attributable to phosphomonoesters, $P i$, phosphodiesters, $P C r$, and the $\gamma, \alpha$, and $\beta$ phosphorus nuclei of $A T P$ respectively. $L=$ lactate; $(a)=$ control spectra, intracellular pH 6.97; $(b)=$ during severe acute hypoxia-ischaemia, intracellular $\mathrm{pH} 6 \cdot 38 ;(c)=$ two hours after hypoxia-ischaemia, intracellular $p H$ 7-23. (Data of Hope et al. ${ }^{14}$ )

malities initially seemed similar to those encountered during an acute hypoxic-ischaemic episode in laboratory animals and illustrated in fig 3 , although they developed much more slowly. The first changes were a fall in $[\mathrm{PCr}]$ and a roughly reciprocal rise in $[\mathrm{Pi}]$, followed by a fall in [ATP] (expressed as a fraction of total phosphorus signal). These changes indicated severe impairment of oxidative phosphorylation (fig 1). Unlike the situation in acute hypoxia-ischaemia, however, intracellular $\mathrm{pH}$ tended to rise. Later [Pi] increased further, well out of proportion to the fall in [PCr], and in fatally damaged brains $\mathrm{PCr}$ and ATP virtually disappeared..$^{12} 19$ In less severely affected infants who recovered, the phosphorus metabolite ratios returned to normal over the course of about two weeks, but sometimes the total phosphorus signal appeared reduced, indicating permanent loss of brain cells. ${ }^{9} 11$ Typical spectra from a baby with birth asphyxia are shown in fig 4. 
The origin of the above sequence of events is likely to lie in an acute intrapartum hypoxicischaemic episode, with effects similar to those illustrated in fig 3 . It can be surmised that an episode of this kind, which may be termed 'primary energy failure', initiates a series of reactions which later cause slowly progressive disruption of oxidative phosphorylation in brain tissue. This disruption may be designated 'secondary energy failure'. Damage to the mitochondrial respiratory electron transport chain as a result of the toxic effects of excitatory neurotransmitters, calcium influx, and free radicals may all play a part, causing failure of utilisation of available oxygen. ${ }^{182021}$ Inadequacy of oxygen supply associated with cerebral oedema and other factors is also likely to be concerned. The rise, rather than fall in intracellular $\mathrm{pH}$, which seems to distinguish secondary from primary energy failure, may be attributed to severe disruption of membrane transport mechanisms.

It has been suggested by Chance $e$ t al that it may be possible to interpret the observed sequence of changes in the brain in terms of metabolic heterogeneity of cells, and that the proportion of seriously compromised and dead cells may be estimated from the magnetic resonance spectroscopy data. ${ }^{22}$

The finding that the phosphorus spectra were usually normal soon after delivery suggests the possibility of early therapeutic intervention to prevent secondary energy failure. Much work is currently under way to explore the effects of 'cerebroprotective' agents such as excitatory neurotransmitter antagonists, calcium entry blockers, and free radical scavengers. The results of investigations

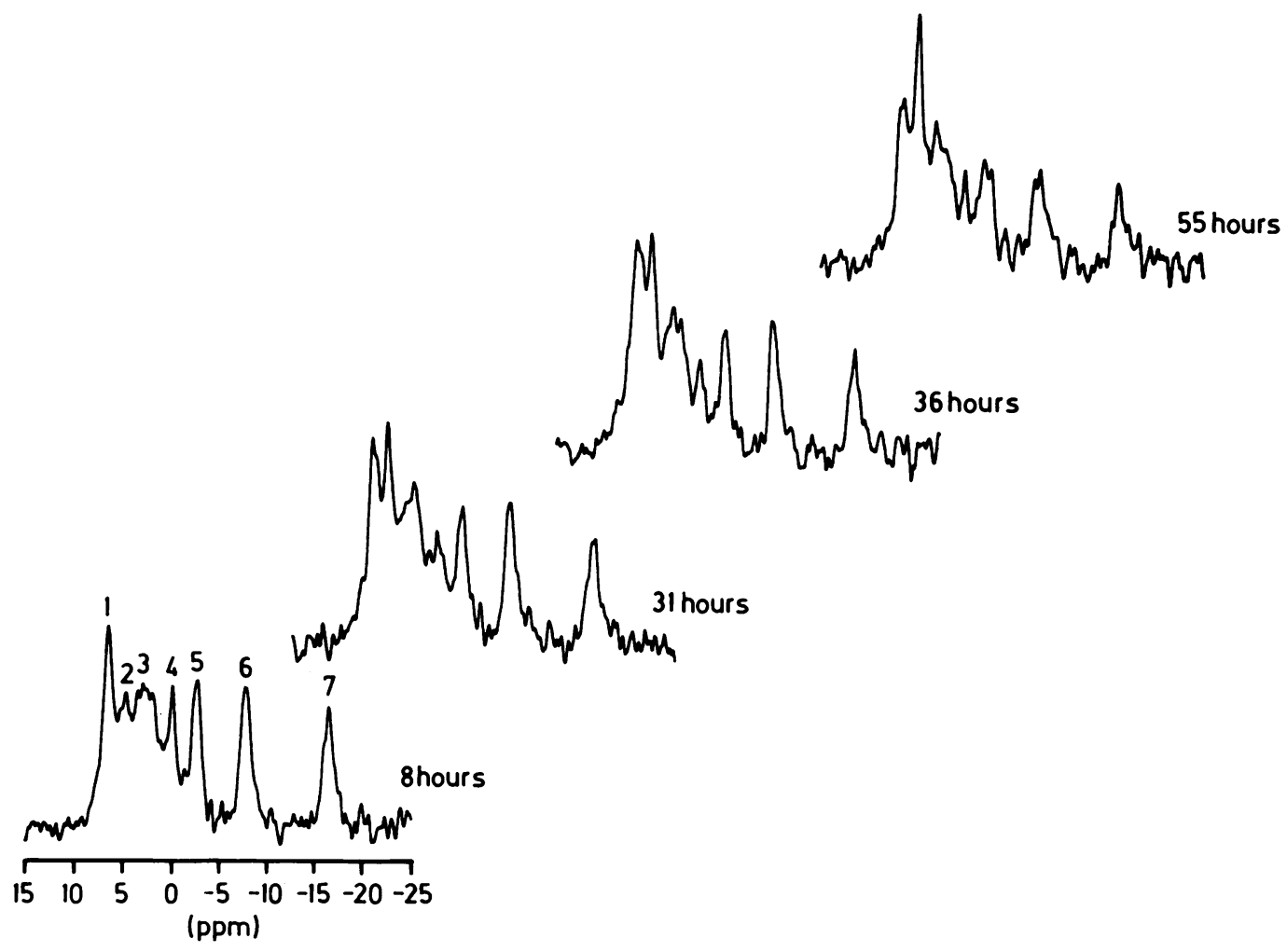

Fig 4 Phosphorus spectra from a baby born at 37 weeks' gestation who had sustained severe birth asphyxia. The peaks (1-7) are attributable to phosphomonoesters, Pi, phosphodiesters, PCr, and the $\gamma, \alpha$, and $\beta$ phosphorus nuclei of ATP, respectively, and the age at the time of each study is indicated. At 8 hours the spectrum was normal, but [PCr]/[Pi] fell to a minimum value of 0.32 at 55 hours, when [ATP]/[total phosphorus] also fell, to 0.04 . Intracellular pH rose to a maximum of 7.28 at 36 hours. The infant died aged 60 hours. (From Azzopardi et al. ${ }^{13}$ ) 
in laboratory animals are encouraging, and suggest that the early administration of these agents may limit or prevent death of brain cells. ${ }^{2123-25}$ While there is no doubt that avoidance of birth asphyxia is the more important goal, if this cannot be achieved, prevention of ensuing irreversible damage may in the future be a realistic possibility. In the meantime, more information about the cerebral haemodynamic and metabolic events that occur during primary and secondary energy failure is urgently needed. One way of obtaining this information is by near infrared spectroscopy, which is discussed below.

\section{Other forms of hypoxic-ischaemic injury}

Abnormal phosphorus spectra indicating impaired oxidative phosphorylation and closely resembling those found in babies with birth asphyxia have been found in a variety of other conditions where hypoxicischaemic injury was suspected, including periventricular leucomalacia, cerebral infarction, and intraparenchymal periventricular haemorrhage. ${ }^{10121326}$ Also, investigations of babies selected for study because of increased cerebral echodensities suggestive of various types of hypoxic-ischaemic injury have shown that oxidative phosphorylation in brain tissue was quite often impaired. ${ }^{19} 26$

Although detailed information is limited, the temporal progression of the spectral abnormalities in all these conditions seems similar to that which follows birth asphyxia, with the implication that the initiating cerebral insult was often around the time of birth. A further implication (at least theoretically) is that cerebroprotective agents may in the future find a role in preventing or ameliorating permanent ill effects-as in the case of birth asphyxia. Conceivably, antenatal protection may eventually become possible in infants at extremely high risk.

\section{Prognosis}

Low $[\mathrm{PCr}] /[\mathrm{Pi}]$ ratios in infants with increased cerebral echodensities are predictive of the later loss of brain tissue. ${ }^{19}$ More recently, a study has been done of the prognostic significance of low values for $[\mathrm{PCr}] /[\mathrm{Pi}]$ and $[\mathrm{ATP}]$ for survival and neurodevelopmental state at the age of 1 year. ${ }^{13}$ Sixty one infants born at 27 to 42 weeks' gestation and suspected of hypoxic-ischaemic brain injury were investigated during the first few days of life. Of the 28 infants whose values for $[\mathrm{PCr}] /[\mathrm{Pi}]$ fell below $95 \%$ confidence intervals for normal control infants, 19 died and seven of the nine survivors developed serious multiple impairments (sensitivity $74 \%$, specificity $92 \%$ positive predictive value for unfavourable outcome 93\%) (fig 5). A significant positive relation was also found between the minimum recorded value for $[\mathrm{PCr}] /[\mathrm{Pi}]$ and the Griffiths
General Quotient at one year. ${ }^{13}$ Further, 11 of the 12 infants with low values for [ATP]/[total phosphorus] died and the single survivor had severe multiple impairments (sensitivity $47 \%$, specificity $97 \%$, positive predictive value for death $91 \%$ ). It was concluded that these data were sufficiently secure that they could in future be taken into account when decisions were made about how far intensive care should be pursued in infants with hypoxic-ischaemic brain injury.

This study also investigated the significance for oxidative metabolism of various different types of cerebral echodensities. It was found that $[\mathrm{PCr}] /[\mathrm{Pi}]$ was more likely to be abnormally low, and prognosis poor, in infants whose echodensities were diffuse or indicated intraparenchymal haemorrhage (in association with intraventricular haemorrhage) than when they were localised and suggestive of periventricular leucomalacia. ${ }^{13}$ In the latter case the lesions were too deep in the brain for abnormalities to be readily detectable by surface-coil magnetic resonance spectroscopy, which acquires signals mainly from the cortex. New developments in the techniques of magnetic resonance spectroscopy will enable this problem to be overcome, and spectra to be obtained from selected volumes of brain tissue. ${ }^{27}$

\section{Near infrared spectroscopy}

Near infrared spectroscopy can be used to measure, at the cotside, a range of indices of brain oxygenation and haemodynamics. It thus provides information complementary to that obtained by magnetic resonance spectroscopy, for reasons indicated in fig 6 , which gives a simplified account of oxidative phosphorylation.

Electrons are generated by the activity of the citric acid cycle. These pass along the respiratory electron transport chain, which is situated in the inner mitochondrial membrane, and provide an electrical potential that leads to the regeneration of ATP from ADP and Pi. At the end of the chain, the electrons reduce cytochrome $\mathrm{aa}_{3}$, which then becomes reoxidised by interaction with molecular oxygen. This reaction accounts for about $95 \%$ of the oxygen consumption of the body.

Near infrared spectroscopy permits changes in the concentrations in brain tissue of oxyhaemoglobin, deoxyhaemoglobin, and oxidised cytochrome $\mathrm{aa}_{3}$ to be measured. The data can be processed to give values for various other variables, including cerebral blood flow and blood volume (see below). Information can therefore be obtained about the supply of oxygen to the tissue and (from the oxygenation (or redox) state of cytochrome $\mathrm{aa}_{3}$ ) about intracellular oxygen availability. 
958 Wyatt, Edwards, Azzopardi, and Reynolds
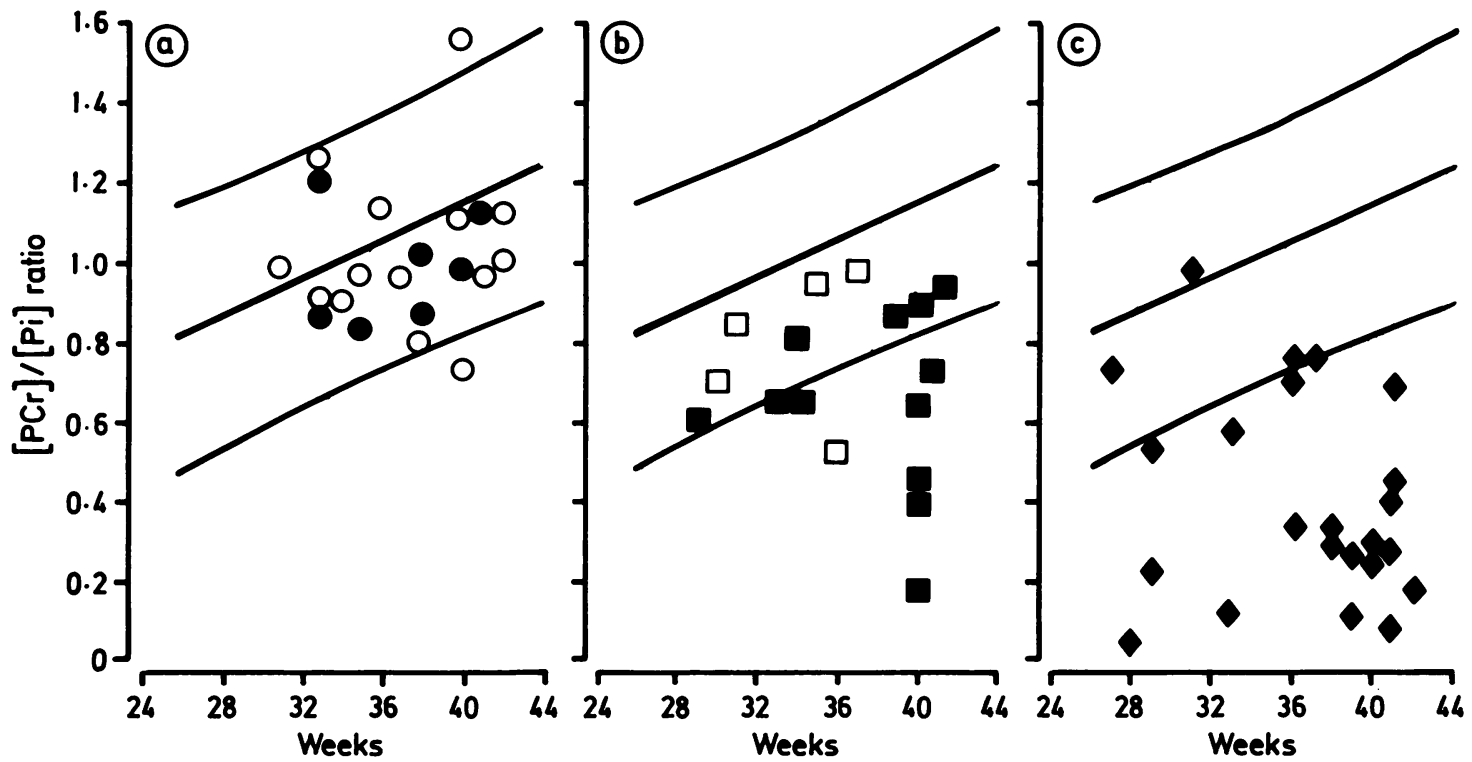

Fig 5 Relation between minimum values for [PCr]/[Pi] recorded during the first few days of life, survival, and neurodevelopmental outcome aged 1 year in 61 infants suspected of hypoxic-ischaemic brain injury. The regression line and 95\% confidence intervals for normal values $v$ gestational plus postnatal age ( $x$ axis) are shown. (a) $O=$ Normal progress at 1 year, and $=$ =minor impairments (disorders of tone or reflexes not causing disability). (b) $\square=$ Major neuromotor impairment causing disability, and $\mathbf{D}=$ multiple major impairments causing disability. (c) $\diamond=D i e d$. (Data of Azzopardi et al. ${ }^{513}$ )
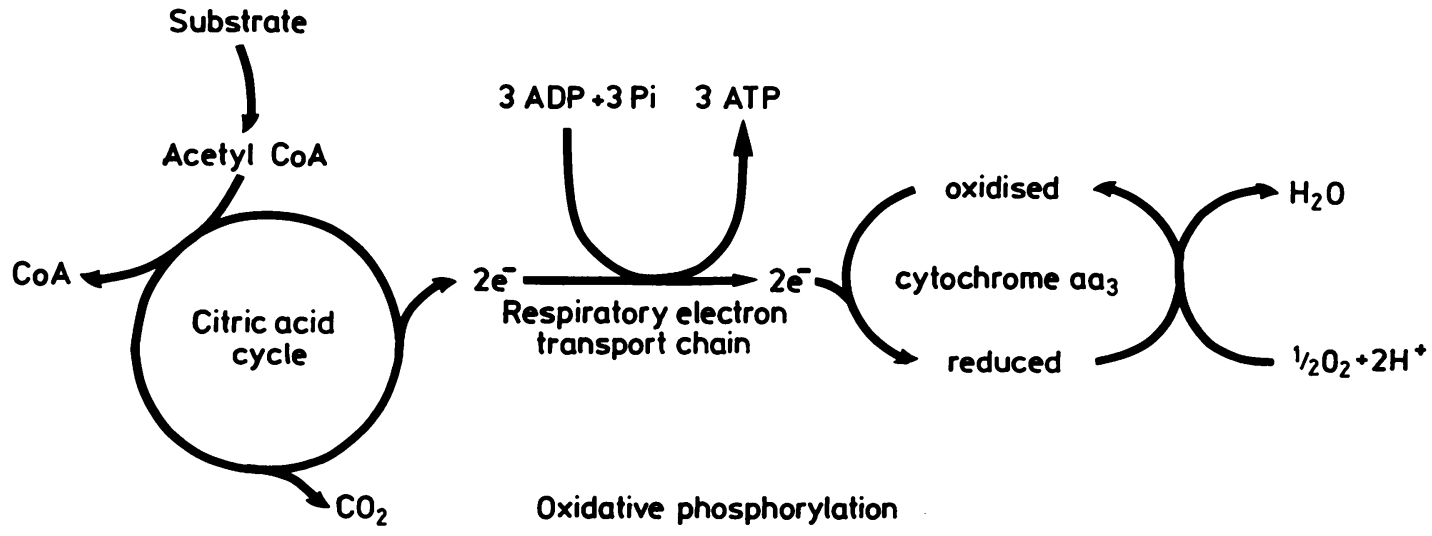

Oxidative phosphorylation

Fig 6 Diagram showing oxidative phosphorylation. 
The principles behind the technique were first clearly established by Jobsis. ${ }^{28}$ They depend on the fact that light in the near infrared region $(700-$ $1000 \mathrm{~nm}$ ) of the spectrum penetrates tissue much more easily than does visible light. With existing technology it is possible to detect near infrared light that has penetrated tissue through distances of about $8 \mathrm{~cm}$, making it possible to perform transmission spectroscopy through all but the largest newborn infant's head. For larger heads observations are still possible by reflectance spectroscopy, though quantitation of the results is not yet so secure.

Oxyhaemoglobin, deoxyhaemoglobin, and oxidised cytochrome $\mathrm{aa}_{3}$ are chromophores which absorb near infrared light in predictable ways. The absorption characteristics of the tissue therefore give information about the presence of these compounds within it. Brazy et al were the first to obtain data from the brains of newborn infants, but quantitation of the compounds was not at that time possible. ${ }^{29} 30$

Quantitative spectroscopy, first performed on newborn infants in $1986,{ }^{31}$ depends on the relation between optical absorption and the concentration of chromophore present. The Beer-Lambert law describing optical absorption may be expressed as: absorption $(\mathrm{OD})=(\mathrm{acLB})+\mathrm{G}$, where $\mathrm{OD}$ is optical densities, $a$ is the absorption coefficient of the chromophore $\left(\mathrm{mM}^{-1} \mathrm{~cm}^{-1}\right), \mathrm{c}$ is concentration $(\mathrm{mM})$, $L$ is the distance between the points where light enters and leaves the tissue $(\mathrm{cm}), B$ is a 'path length factor' that takes account of the scattering of light in the tissue (which causes the optical pathlength to be greater than $L$ ), and $G$ is a factor related to the geometry of the tissue. If $\mathrm{L}, \mathrm{B}$, and $\mathrm{G}$ remain constant, then changes in chromophore concentration can be obtained from the expression: $\Delta \mathrm{c}=$ $\Delta \mathrm{OD} / \mathrm{aLB}$.

The absorption coefficients of oxyhaemoglobin and deoxyhaemoglobin have been obtained from in vitro studies, and of cytochrome $\mathrm{aa}_{3}$ from observations from the brain in rats given exchange transfusions of a fluorocarbon blood substitute to remove haemoglobin. ${ }^{32}$ The pathlength factor $B$ has been obtained by several different methods, ${ }^{31-33}$ including time of flight measurements of an ultrashort pulse of light across the head. ${ }^{33}$ These methods gave a value for $B$ of about $4 \cdot 3$ and this is the value now used for quantitation of oxyhaemoglobin, deoxyhaemoglobin, and oxidised cytochrome $\mathrm{aa}_{3}$ in the brains of newborn infants. In practice, absorption at several different wavelengths is measured and an algorithm is used to convert changes in optical absorption to changes in concentration. ${ }^{12} 3132$ (Absorption by chromophores in extracerebral tissues is negligible.)
OBSERVATIONS IN NEWBORN INFANTS

For the observations to be made, new portable apparatus has been designed and built. ${ }^{34}$ Near infrared light at the requisite wavelengths is transmitted into the parietal region through a flexible fibreoptic bundle, and light emerging from the opposite parietal region is collected by an identical bundle and conveyed to a sensitive photomultiplier tube. The distance $\mathrm{L}$ is measured with calipers. A controlling computer detects the changes in optical absorption and converts them to changes in chromophore concentration. The results are displayed instantaneously at the cotside and recorded

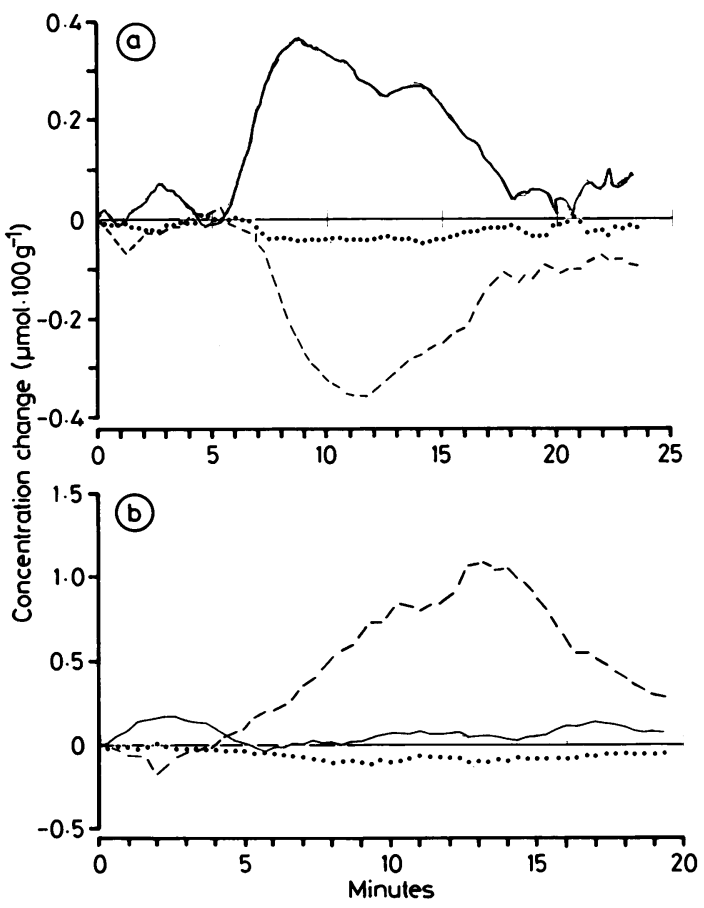

Fig 7 Changes in the intracerebral concentrations of oxyhaemoglobin (- - - - ), deoxyhaemoglobin ( $)$ and oxidised cytochrome $a a_{3}(. .$.$) in two$ infants: (a) born at 29 weeks' gestation and studied aged 1 day, and (b) born at 36 weeks' gestation and studied aged 4 days. Both infants had hyaline membrane disease necessitating mechanical ventilation. Changes are shown during: a-alterations in $\mathrm{SaO}_{2}$, which was reduced from $95 \%$ to $88 \%$ at five minutes and then returned to $95 \%$. $b$-alterations in $\mathrm{PaCO}_{2}$, which increased from $6.1 \mathrm{kPa}$ to $7 \cdot 2 \mathrm{kPa}$ at 12 minutes, and then fell to $6 \cdot 2 \mathrm{kPa}$. As expected alterations in $\mathrm{SaO}_{2}$ were followed by approximately reciprocal changes in oxyhaemoglobin and deoxyhaemoglobin. The increase in $\mathrm{PaCO}_{2}$ caused a rise in oxyhaemoglobin but no change in deoxyhaemoglobin, presumably because of an associated increase in cerebral blood flow. 
on computer disk for subsequent analysis.

Alterations in the intracerebral concentrations of oxyhaemoglobin, deoxyhaemoglobin, and cytochrome $\mathrm{aa}_{3}$ have been quantified in sick newborn infants during small spontaneous or induced changes in arterial oxygen saturation $\left(\mathrm{SaO}_{2}\right)$ and $\mathrm{PaCO}_{2}$. Typical results are illustrated in fig 7 . The data may then be further analysed to provide absolute values for a number of important variables, including cerebral blood volume, cerebrovascular response to changing $\mathrm{PaCO}_{2}$ and cerebral blood flow.

\section{Cerebral blood volume}

Cerebral blood volume may be quantified by observing the effect of a small gradual change in $\mathrm{SaO}_{2}$ on oxyhaemoglobin and deoxyhaemoglobin ${ }^{30}$ If cerebral haemodynamics do not change during this manoeuvre cerebral blood volume can be calculated from the equation: cerebral blood volume $\left(\mathrm{ml} \cdot 100 \mathrm{~g}^{-1}\right)=(\Delta$ oxyhaemoglobin $-\Delta$ deoxyhaemoglobin $) / 2\left(\mathrm{tHb} \cdot \mathrm{R} \cdot \Delta \mathrm{SaO}_{2}\right)$ where $\mathrm{tHb}$ is the central total haemoglobin concentration $\left(\mathrm{mM} \cdot \mathrm{ml}^{-1}\right)$, and $\mathrm{R}$ is the cerebral:large vessel haematocrit ratio (assumed to be 0.69).

Mean cerebral blood volume in 12 preterm and full term newborn infants undergoing intensive care who were thought to have normal brains was $1.7 \mathrm{ml} \cdot 100 \mathrm{~g}^{-1}$, whereas in 10 comparable infants with brain injury (mostly hypoxic-ischaemic) cerebral blood volume was significantly higher, 3.0 $\mathrm{ml} \cdot 100 \mathrm{~g}^{-1}$ (JS Wyatt, M Cope, DT Delpy, et al, unpublished observations). The highest values were found in infants who had sustained severe birth asphyxia, presumably because of the effects of vasodilator substances.

\section{Cerebrovascular response to changes in $\mathrm{PaCO}_{2}$}

The response of cerebral blood volume to small changes $(\sim 1 \mathrm{kPa})$ in $\mathrm{PaCO}_{2}$ can readily be observed by near infrared spectroscopy. Preliminary studies in infants with normal brains have given values of about $0.5 \mathrm{ml} \cdot 100 \mathrm{~g}^{-1} \cdot \mathrm{kPa}^{-1}$, whereas in infants with birth asphyxia a pronounced reduction or absence of response was found. ${ }^{35}$ Fig 8 shows that cerebral blood volume may be increased, and cerebrovascular response to changes in $\mathrm{PaCO}_{2}$ reduced, before the development of secondary energy failure, as detected by magnetic resonance spectroscopy. It is likely that in the future these and other near infrared spectroscopy indices will be useful for identifying infants whose prognosis is particularly bad and in whom the use of new cerebroprotective agents might be tested by controlled trials.

Cerebral blood flow

It has recently been shown that cerebral blood flow
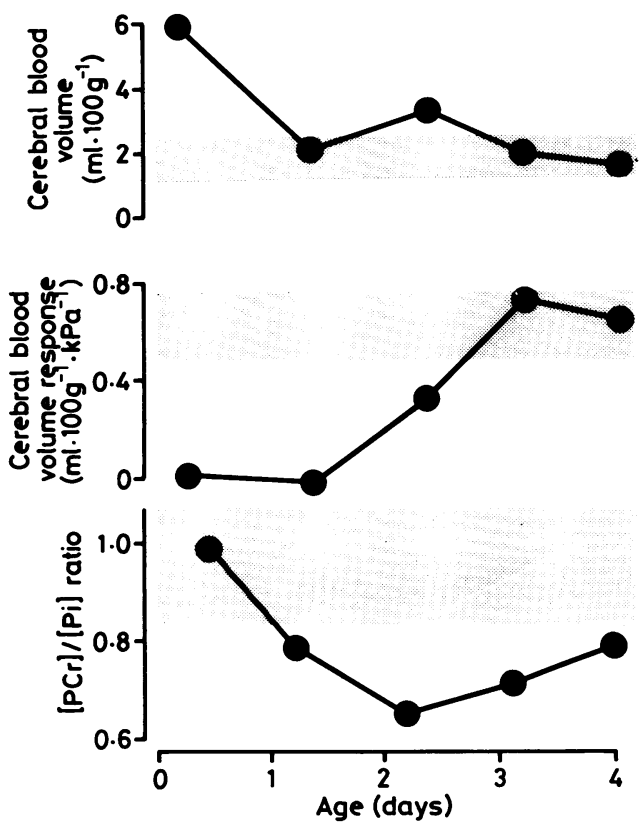

Fig 8 Cerebral blood volume, its response to small changes in arterial carbon dioxide tension, and $[P C r] /[P i]$ in an infant with severe birth asphyxia born at 36 weeks' gestation: he developed cerebral atrophy and died aged 7 weeks. Normal ranges are shaded.

can be measured by near infrared spectroscopy ${ }^{36}$ using an application of the Fick principle, which states that the rate of accumulation of a tracer substance in an organ is equal to the difference between the rate of arrival and the rate of departure of that substance. When a substance is suddenly introduced into the arterial blood a measurement of the amount accumulated in the organ can be made a a specific time later. If this time is less than the transit time through the organ, the tracer will not appear in the venous blood and flow can be measured as the ratio of tracer accumulated to the quantity of tracer introduced. The near infrared spectroscopy method uses oxyhaemoglobin as the tracer. A sudden change in $\mathrm{SaO}_{2}$-measured with a pulse oximeter on the ear-is induced by altering the inspired oxygen concentration. The amount of extra oxyhaemoglobin introduced into the brain can then be calculated, and related to the amount accumulated, which is estimated from the change in intracerebral oxyhaemoglobin (fig 9). The expression used to make the calculation is: cerebral blood flow $\left(\mathrm{ml} \cdot 100 \mathrm{~g}^{-1} \cdot \mathrm{min}^{-1}\right)=(\mathrm{K} \Delta$ [oxyhaemoglobin] $) /$ $\left([\mathrm{tHb}]_{\mathrm{o}} \int^{t}\left(\Delta \mathrm{Sa}_{2}\right) \mathrm{dt}\right.$, where $\mathrm{K}$ is $0 \cdot 89$, a constant 


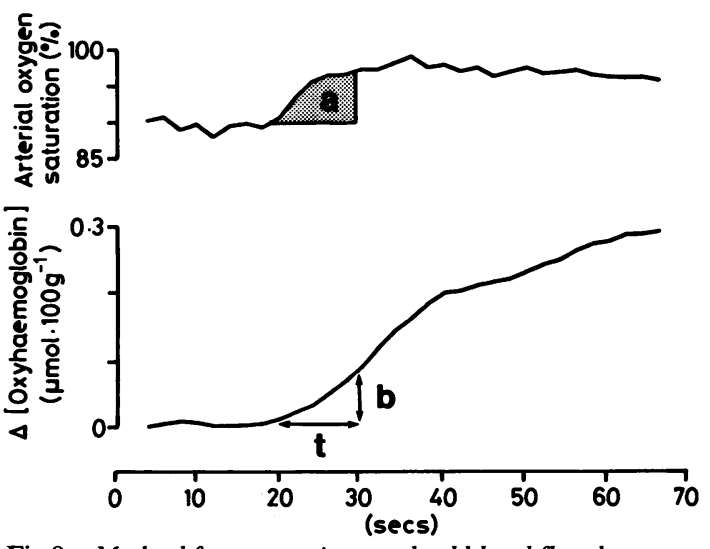

Fig 9 Method for measuring cerebral blood flow by near infrared spectroscopy. Shaded area $(a)={ }_{o}{ }^{t}(\Delta$ arterial oxygen saturation)dt, and $(b)=\Delta$ oxyhaemoglobin. Terms (a) and (b) were used to derive flow. (From Edwards et al. ${ }^{36}$ )

reflecting cerebral to large vessel haematocrit ratio, the molecular weight of haemoglobin and cerebral tissue density; and [tHb] is total haemoglobin concentration obtained from a large vessel.

Thirty one measurements of cerebral blood flow in nine ill, mostly very preterm, infants gave values of about $18 \mathrm{ml} \cdot 100 \mathrm{~g}^{-1} \cdot \mathrm{min}^{-1}$, which appeared comparable with earlier observations made on similar infants using the ${ }^{133}$ xenon method, ${ }^{37}$ or positron emission tomography. ${ }^{38}$ Validation of the near infrared spectroscopy method has been performed by making simultaneous measurements of blood flow in the adult forearm by near infrared spectroscopy and by venous occlusion plethysmography. ${ }^{39}$ The results corresponded closely.

The effect on cerebral blood flow of the administration of intravenous indomethacin $\left(0 \cdot 1-0.2 \mathrm{mg} \cdot \mathrm{kg}^{-1}\right)$ for closure of a patent ductus arteriosus has been tested in eight infants. ${ }^{40}$ Cerebral blood flow always fell, from a median value of $23 \mathrm{ml} \cdot 100 \mathrm{~g}^{-1} \cdot \mathrm{m}^{-1}$ to $9 \mathrm{ml} \cdot 100 \mathrm{~g}^{-1} \cdot \mathrm{m}^{-1}$. Cerebral blood volume and its response to changing $\mathrm{PaCO}_{2}$ and cerebral oxygen delivery, also fell. No recovery of these variables was seen in up to two hours of continuing observations.

\section{Summary and conclusions}

Hypoxic-ischaemic injury to the brain is an important cause of perinatal death and seems to be the commonest cause of permanent neurodevelopmental disability in newborn infants who survive after intensive care. If this type of brain injury is to be prevented and treatment put on a rational basis, non-invasive methods are required for defining its mechanisms. This review has considered two such methods: magnetic resonance spectroscopy and near infrared spectroscopy.

Magnetic resonance spectroscopy is used to measure, in brain tissue, the concentrations of the 'high energy' phosphorus metabolites that are dependent for their synthesis on the processes of oxidative phosphorylation. Intracellular $\mathrm{pH}$ can also be measured. Normal maturational changes in the brain have been defined and abnormalities detected in a range of conditions where hypoxic-ischaemic injury was suspected to have occurred. In laboratory animals the acute effects of curtailment of oxygen supply to the brain ('primary' energy failure) have been observed, and the effects of two commonly used treatments, infusions of sodium bicarbonate and glucose, have been tested.

After resuscitation of newborn infants from severe intrapartum asphyxia, a latent period has often been noted before energy failure became detectable. This 'secondary' energy failure is due to a variety of damaging reactions initiated by the acute hypoxicischaemic episode and reperfusion of the brain. It is possible that in the future irreversible injury to brain cells following the episode may be prevented or ameliorated by the prompt use of cerebroprotective agents.

The extent of abnormalities detected by magnetic resonance spectroscopy has prognostic implications: evidence of severe energy failure in the first days of life was regularly associated with subsequent death or with severe neurodevelopmental impairments.

Many technical developments in magnetic resonance spectroscopy are under way, particularly employing proton $\left({ }^{1} \mathrm{H}\right)$ spectroscopy, which will allow the intracerebral concentrations of a wide range of metabolites, including neurotransmitters, to be measured. The combination of spectroscopy with magnetic resonance imaging will permit quantitative data to be obtained from selected volumes within the brain.

Near infrared spectroscopy is used to make observations at the cotside of the intracerebral concentrations of the chromophores oxyhaemoglobin, deoxyhaemoglobin, and oxidised cytochrome $\mathrm{aa}_{3}$, and it therefore provides information complementary to that obtained by magnetic resonance spectroscopy. Measurements can also be made of cerebral blood flow, cerebral blood volume, and other haemodynamic indices; in addition, the reactivity of the cerebral circulation can be tested. The effects of therapeutic manoeuvres and drugs such as indomethacin can be observed. Near infrared spectroscopy is already providing information about the haemodynamic events that precede and accompany secondary energy failure in newborn infants 
and in laboratory animals: it seems likely to go into routine use for monitoring brain oxygenation and haemo-dynamics in ill babies, and for guiding treatment.

We thank Mr R Aldridge, Mr EB Cady, Mr M Cope, Mr DT Delpy, Dr RM Gardiner, Dr PA Hamilton, Dr PL Hope, Miss C Richardson, Dr AL Stewart, Professor DR Wilkie, FRS, Dr S Wray, and many members of the staff of the neonatal unit and the departments of paediatrics, medical physics and bioengineering, and physiology for their help, and we are grateful to Mrs G Harris for preparing the manuscript. This work was supported by Action Research for the Crippled Child, the DHSS, Hamamatsu Photonics KK, the Medical Research Council, the Wellcome Trust, and the Wolfson Foundation.

\section{References}

1 Alberman ED. The epidemiology of congenital defects: a pragmatic approach. In: Adinolfi $M$, Benson P, Gianelli F, Seller M, eds. Paediatric research: a genetic approach. London: SIMP Heinemann, 1982:1-28.

2 Cady EB, Costello AMdeL, Dawson MJ, et al. Non-invasive investigation of cerebral metabolism in newborn infants by phosphorus nuclear magnetic resonance spectroscopy. Lancet 1983;i:1059-62.

3 Younkin DP, Delivoria-Papadopolous M, Leonard J, et al. Unique aspects of human newborn cerebral metabolism evaluated with phosphorus nuclear magnetic resonance spectroscopy. Ann Neurol 1984;16:581-6.

${ }^{4}$ Gadian DG. Nuclear magnetic resonance and its application to living systems. Oxford: Clarendon Press, 1982.

5 Azzopardi D, Wyatt JS, Hamilton PA, et al. Phosphorus metabolites and intracellular $\mathrm{pH}$ in the brains of normal and small-for-gestational-age infants investigated by magnetic resonance spectroscopy. Pediatr Res (in press).

6 Petroff OAC, Prichard JW, Behar KL, Alger JR, den Hollander JA, Shulman RG. Cerebral intracellular $\mathrm{pH}$ by $31 \mathrm{P}$ magnetic resonance spectroscopy. Neurology 1985;35:781-8.

7 Tofts PS, Wray S. Changes in brain phosphorus metabolites during the postnatal development of the rat. J Physiol 1985;359: 417-29.

${ }^{8}$ Cady EB, Chu A, Costello AMdeL, et al. Brain intracellular pH and metabolism during hypercapnia and hypocapnia in the newborn lamb. J Physiol 1987;382:1-14.

9 Hope PL, Costello AMdeL, Cady EB, et al. Cerebral energy metabolism studied with phosphorus NMR spectroscopy in normal and birth-asphyxiated infants. Lancet 1984;ii:366-70.

${ }^{10}$ Hope PL, Reynolds EOR. Investigation of cerebral energy metabolism in newborn infants by phosphorus magnetic resonance spectroscopy. Clin Perinatol 1985;12:261-75.

11 Delpy DT, Cope MC, Cady EB, et al. Cerebral monitoring in newborn infants by magnetic resonance and near infrared spectroscopy. Scand J Clin Lab Invest 1987;47(suppl 188):9-17.

12 Reynolds EOR, Wyatt JS, Azzopardi D, et al. New non-invasive methods for assessing brain oxygenation and haemodynamics. Br Med Bull 1988;44:1052-75.

13 Azzopardi D, Wyatt JS, Cady EB, et al. Prognosis of infants with hypoxic-ischaemic brain injury assessed by phosphorus magnetic resonance spectroscopy. Pediatr Res (in press).

14 Hope PL, Cady EB, Chu A, Delpy DT, Gardiner RM, Reynolds EOR. Brain metabolism and intracellular $\mathrm{pH}$ during ischaemia and hypoxia. An in vivo $31 \mathrm{P}$ and $1 \mathrm{H}$ nuclear magnetic resonance study in the lamb. $J$ Neurochem 1987;49:75-82.

15 Hope PL, Cady EB, Delpy DT, Ives NK, Gardiner RM, Reynolds EOR. Brain metabolism and intracellular $\mathrm{pH}$ during ischaemia: The effects of systemic glucose and bicarbonate administration studied by $31 \mathrm{P}$ and $1 \mathrm{H}$ nuclear magnetic resonance spectroscopy in vivo in the lamb. $J$ Neurochem 1988;50: 1394-402.
${ }^{16}$ Sessler D, Mills P, Gregory G, Litt L, James T. Effect of bicarbonate on arterial and brain intracellular $\mathrm{pH}$ in neonatal rabbits recovering from hypoxic lactic acidosis. J Pediatr 1987;11:817-23.

17 Laptook AR, Corbett RJT, Nguyen T, Peterson J, Nunnally $\mathrm{RL}$. Alterations in cerebral blood flow and phosphorylated metabolites in piglets during and after partial ischemia. Pediatr Res 1988;23:206-11.

${ }^{18}$ Siesjo BK. Brain energy metabolism. New York: Wiley, 1978.

19 Hamilton PA, Hope PL, Cady EB, Delpy DT, Wyatt JS, Reynolds EOR. Impaired energy metabolism in brains of newborn infants with increased cerebral echodensities. Lancet 1986;i:1242-6.

${ }^{20}$ Siesjo BK. Cerebral circulation and metabolism. J Neurochem 1984;60:883-908.

${ }^{21}$ Schwarcz R, Meldrum B. Excitatory amino acid antagonists provide a therapeutic approach to neurological disorders. Lancet 1985;ii:140-3.

22 Chance B, Leigh JS, Nioka S, Sinwell T, Younkin D, Smith D. An approach to the problem of metabolic heterogeneity in brain: ischemia and reflow after ischemia. Ann NY Acad Sci 1987;508:309-19.

${ }^{23}$ Rothman SM, Olney JW. Excitotoxicity and the NMDA receptor. Trends in Neurosciences 1987;10:299-302.

${ }^{24}$ McDonald JW, Silverstein FS, Johnston MV. MK-801 protects the neonatal brain from hypoxic-ischemic damage. Eur $J$ Pharmacol 1987;140:359-61.

25 Thiringer K, Hrbek A, Karlson K, Rosen KG, Kjellmer I. Postasphyxial cerebral survival in newborn sheep after treatment with oxygen free radical scavengers and a calcium antagonist. Pediatr Res 1987;22:62-6.

26 Younkin D, Medoff-Cooper B, Guillet R, Sinwell T, Chance B, Delivoria-Papadopoulos $M$. In vivo $31 \mathrm{P}$ nuclear magnetic resonance of chronic changes in cerebral metabolites following neonatal intraventricular haemorrhage. Pediatrics 1988;82:331-6.

${ }^{27}$ Hope PL, Blackledge MJ, Ives NK, Rajagopalan B, Sutton P, Radda GK. Spatial localisation of magnetic resonance spectra from neonatal brains. Pediatr Res 1988;24:264.

28 Jobsis FF. Noninvasive infrared monitoring of cerebral and myocardial oxygen sufficiency and circulatory parameters. Science 1977;198:1264-7.

29 Brazy JE, Lewis DV, Mitnick MH, Jobsis van der Vliet F. Noninvasive monitoring of cerebral oxygenation in preterm infants: preliminary observations. Pediatrics 1985;75:217-25.

30 Brazy JE, Lewis DV. Changes in cerebral blood volume and cytochrome aa3 during hypertensive peaks in preterm infants. $J$ Pediatr 1986;108:983-7.

31 Wyatt JS, Cope M, Delpy DT, Wray S, Reynolds EOR. Quantitation of cerebral oxygenation and haemodynamics in sick newborn infants by near infrared spectrophotometry. Lancet 1986;ii:1063-6.

32 Wray S, Cope M, Delpy DT, Wyatt JS, Reynolds EOR. Characterisation of near infrared absorption spectra of cytochrome aa3 and haemoglobin for the non-invasive monitoring of cerebral oxygenation. Biochim Biophys Acta 1988;933:184-92.

33 Delpy DT, Cope M, van der Zee P, Arridge S, Wray S, Wyat JS. Estimation of optical pathlength through tissue from direct time of flight measurement. Phys Med Biol 1988;33:1433-42.

34 Cope M, Delpy DT. A system for long term measurement of cerebral blood and tissue oxygenation in newborn infants. Med Biol Eng Comp 1988;26:289-94.

${ }^{35}$ Wyatt JS, Edwards AD, Azzopardi D, et al. Cerebral haemodynamics during failure of oxidative phosphorylation following birth asphyxia. Pediatr Res (in press).

${ }^{36}$ Edwards AD, Wyatt JS, Richardson C, Delpy DT, Cope M, Reynolds EOR. Cotside measurement of cerebral blood flow in ill newborn infants by near infrared spectroscopy. Lancet 1988;ii:770-1.

${ }^{37}$ Greisen G. Cerebral blood flow in preterm infants in the first week of life. Acta Paediatr Scand 1986;75:43-51. 
38 Volpe JJ, Hersovitch P, Perlman JM, Raichle ME. Positron emission tomography in the newborn: extensive impairement of regional cerebral blood flow with intraventricular hemorrhage and hemorrhagic intracerebral involvement. Pediatrics 1983;72: 589-601.

39 Edwards AD, Reynolds EOR, Richardson CE, Wyatt JS. Estimation of blood flow using near infra-red spectroscopy. J Physiol 1989;410:50P.
${ }^{40}$ Edwards AD, Richardson CE, Wyatt JS, Delpy DT, Cope M, Reynolds EOR. Effect of indomethacin on cerebral oxygenation and haemodynamics investigated by near infrared spectroscopy. Pediatr Res (in press).

Correspondence to Professor EOR Reynolds, Department of Paediatrics, University College and Middlesex School of Medicine, The Rayne Institute, University Street, London WC1E 6JJ. 